\title{
COLECIONISMO A PARTIR DA PERSPECTIVA DE GÊNERO
}

\begin{abstract}
Resumo
$\mathrm{O}$ artigo aborda o colecionismo e as coleções a partir da perspectiva de gênero e busca questionar a hegemonia da lógica androcêntrica presente na maioria dos museus brasileiros. Com isso, argumenta sobre a importância de estudos que coloquem em evidência as mulheres colecionadoras e as coleções formadas por elas possibilitando um olhar abrangente e crítico sobre as práticas colecionistas.
\end{abstract}

Ana Cristina Audebert Ramos de Oliveira

\section{Palavras-chave}

Museologia, colecionismo, gênero, mulheres, museu.

\begin{abstract}
The article covers on the collecting and collections from the gender perspective and seeks to question the hegemony of androcentric logic present in most Brazilian museums. With that, argues about the importance of studies that put in evidence the women collectors and collections formed by them providing a comprehensive and critical look on collectors practices.
\end{abstract}

\section{Keywords}

Museology, collecting, gender, women, museum.

\section{Introdução}

Os diferentes olhares para o colecionismo nos estudos atuais parecem apontar para o fato de que, enquanto prática social, é preciso superar as categorias de semióforo² (Pomian, 1985), nostalgia (Baudrillard, 2006), relíquia (Barroso, 195I) entre outras.As pesquisas contemporâneas buscam demonstrar a vinculação das coleções a projetos, ideologias e intenções, colaborando para desnaturalizar o colecionismo, observando "as diferenças semânticas do ato de colecionar, visto que cada prática se insere em diferentes perspectivas". (Magalhães e Bezerra, 2012:10).

O colecionismo ilustrado é produto de um universo letrado da elite, da burguesia e da classe média e também é uma prática social marcada por relações de gênero.Abordagens que colocam em questão a história e o desenvolvimento do colecionismo ilustrado situam-no como um fenômeno associado às sociedades ocidentais modernas e contemporâneas. Outros trabalhos salientam o aspecto universal do colecionismo, entendendo que o fenômeno está presente em todas as culturas ainda que com significados diversos. Ambas as abordagens coincidem

I Museóloga. (UNIRIO). Mestra em História da Cultura (PUC/RJ). Doutora em Museologia e Patrimônio. (PPG-PMUS/UNIRIO/MAST). Professora do Departamento de Museologia da Universidade Federal de Ouro Preto. (DEMUL/UFOP).Email: ana_audebert@yahoo.com.br

2 Segundo Pomian, uma coleção é composta de semióforos que diferente dos objetos úteis são objetos destituídos de valor de uso. Não servem mais para serem usados, mas para serem expostos ao olhar sendo dotados de um valor de troca fundamentado no seu significado. POMIAN, Krzysztof. Coleção. Enciclopédia Einaudi, v. I, I 984, p. 5 I-86. 
Colecionismo a partir da perspectiva de gênero

no entendimento sobre a especificidade do ato de selecionar e reunir objetos a partir de critérios específicos e de ações que alienam esses objetos do sistema lógico primordial do qual foram retirados (a lógica do uso ou da vida cotidiana) inserindo-os em outras lógicas próprias de cada colecionador ou grupo. Para James Clifford, “A história crítica do colecionar diz respeito ao que os grupos específicos e indivíduos decidem preservar, valorizar e trocar dentre o que há no mundo material." (Clifford, 1994: 73)

Neste sentido, é preciso também observar as relações de gênero no estudo do colecionismo. É necessário perguntar se as coleções que estão nos museus refletem e tornam visíveis as contribuições das mulheres nas memórias que essas instituições e processos preservam e contam. E se fazem é preciso se perguntar como fazem. A partir de quais perspectivas? Conformistas ou renovadoras? Emancipatórias ou submetidas?

Ao olhar para a realidade tomando gênero como eixo central de análise observamos as relações entre mulheres e homens e podemos questionar os efeitos dessas relações em diversas esferas da vida cotidiana ${ }^{3}$ (familiar/ doméstico, trabalho/profissional, lazer/descanso, atividades sociais, etc.;). Isso implica no reconhecimento de que os papéis e as condições de mulheres e homens respondem a uma construção social situada historicamente e sujeita a mudanças.

Pensar gênero permite revisar e analisar a condição das mulheres em diversos contextos revelando na maioria das vezes situações de desigualdade, demonstrando assimetrias nas relações de poder presentes nas experiências de mulheres e homens em nossa sociedade. Também nos ajuda a enxergar e criticar alguns discursos (religiosos, artísticos, médicos) que têm sido sustentados pelo sistema patriarcal dominante. Deste modo, problematizar gênero nas relações cotidianas se torna um instrumento que fortalece a ideia de transformação das realidades sociais.

Esses discursos configuram representações mentais mais ou menos estáveis das mulheres a partir de papéis e estereótipos relacionados à feminilidade. Segundo Mary Del Priore, entre os séculos XII e XVIII, a Igreja identificava nas mulheres uma das formas do mal sobre a terra. Quer na filosofia, na moral ou na ética do período, a mulher era considerada um ninho de pecados. Os mistérios da fisiologia feminina, ligados ao ciclo da Lua, ao mesmo tempo em que seduziam os homens, os repugnavam. O fluxo menstrual, os odores, o líquido amniótico, as expulsões do parto e as secreções de sua parceira os repeliam. $O$ corpo feminino era considerado impuro. (Del Priore, 20I I). A história da Inquisição demonstra como a mulher, seu corpo e seus conhecimentos foram perseguidos

3 Segundo Agnes Heller "A vida cotidiana é, em grande medida, heterogênea; e isso sob vários aspectos, sobretudo no que se refere ao conteúdo e à significação ou importância de nossos tipos de atividade. São partes orgânicas da vida cotidiana: a organização do trabalho e da vida privada, os lazeres e o descanso, a atividade social sistematizada, o intercâmbio e a purificação. Mas a significação da vida cotidiana, tal como seu conteúdo, não é apenas heterogênea, mas igualmente hierárquica. Todavia, diferentemente da circunstância da heterogeneidade, a forma concreta da hierarquia não é eterna e imutável, mas se modifica de modo específico em função das diferentes estruturas econômico-sociais." Ver: HELLER, Agnes. O Cotidiano e a História. São Paulo: Editora Paz e Terra, 2000, p. 18. 
Ana Cristina Audebert Ramos de Oliveira

e condenados à feitiçaria e bruxaria ${ }^{4}$. Os documentos da época e também os livros que têm sido escritos sobre esse fenômeno revelam que milhares de mulheres foram queimadas nas fogueiras pelos crimes de "lançar mauolhado sobre crianças", "desfazer amor e casamento", "receber presentes do diabo","praticar cerimônias em pacto com o demônio", "cometer atos contra a honestidade e a religião", etc. (Novinsky, 1982).

Ao mesmo tempo a própria Igreja fomentou o culto à Virgem Maria, uma mulher ideal cujo corpo não era impuro e que concebeu sem o pecado original. Ao lado da mulher vista como mal e impura soma-se a representação da mulhermãe como pura e casta constatada através de muitas imagens e representações da Madona onde vemos a Mãe como modelo de beleza e virtude.

No ocidente, as representações da mulher na literatura e nas artes nos séculos XVIII e XIX também são abundantes em idealizações que transitavam entre a Musa, o Anjo e a Mulher Fatal. Segundo Mireille Dottin-Orsini as estátuas alegóricas que a arte oficial multiplicava em toda a Europa impunham a obsessão feminina em três dimensões: natureza e cultura, luxúria e castidade, verdade e mentira.A mulher e seu corpo serviam para tudo:"mulheres nuas sobre pedestais em lugares públicos, cabriolando nas fachadas dos edifícios, ornamentando os relógios e canteiros...: eram a Justiça, a Ciência, a Eletricidade, a Indústria, mas também os Rios, os Continentes, sem falar das Colônias". (Dottin-Orsini, 1996: II). Também os museus, em especial os de arte, são locais onde a mulher foi e é exposta continuamente, em paredes atapetadas de mil nádegas rosadas, despidas de pelos, mas com longas e sensuais cabeleiras nas muitas representações de pintura acadêmica do século XIX. O movimento Guerrilla Girls ${ }^{5}$ denunciou no final dos anos 1980 os museus de arte como espaços de dominação muito alinhados com o sistema patriarcal e viram na falta de representação de mulheres artistas $\mathrm{x}$ abundância de mulheres representadas um tipo de violência simbólica que persiste ainda hoje. Qual será a representatividade das mulheres artistas nos museus de arte brasileiros? Os museus possuem interesse em evidenciar a produção das artistas com a intenção de discutir os lugares das mulheres na sociedade e nas artes em geral? Ou essa produção tende a ser tratada de forma neutra, sem que a condição feminina seja trazida à tona? ${ }^{6}$

4 Foi na Espanha e Portugal, durante a época moderna, isto é, nos séculos XVI, XVII e XVIII que a Inquisição alcançou seu apogeu e apesar de todo o aparato religioso e da auréola divina com que o Tribunal do Santo Ofício se revestiu, apesar das alegadas funções santas, foi uma instituição vinculada ao Estado como aparelho para o controle social. Respondeu aos interesses das facções do poder: coroa, nobreza e clero.Transmitia à massa dos fiéis, aos leigos, uma mensagem de medo e terror, que tornava a maioria da sociedade submissa e obediente.A onda de perseguição às feiticeiras na época moderna alastrou-se por toda a Europa, principalmente Alemanha, Inglaterra, Itália e França. Em Portugal numerosas bruxas compareceram aos autos-de-fé durante os séculos XVI, XVII e XVIII, sendo muitas originárias do Brasil.Ver: Novinsky, Anita. A inquisição. São Paulo: Editora Brasiliense, 1982.

$5 \bigcirc$ movimento feminista Guerrilla Girls atua desde 1985. Seu manifesto inicial e todas as ações que praticam até hoje podem ser consultadas no site http://www.guerrillagirls.com/chronology/. Agradeço a querida colega Karina Muniz Viana que me informou sobre esse movimento.

6 Neste sentido é interessante registrar a Exposição “Mulheres, artistas e brasileiras", realizada em 20 I I, e que reuniu 76 obras de 49 artistas. A exposição se propôs a apresentar a produção artística de brasileiras desde o início do século $X X$ aos primeiros anos do século $X X I$ e obras contemporâneas. Para uma análise da exposição em questão ver: OLIVEIRA, Ana Cristina Audebert Ramos de; QUEIROZ, Marijara Souza de. Museologia - Substantivo Feminino: Reflexões 
Colecionismo a partir da perspectiva de gênero

Os discursos médicos e sanitaristas que figuram coroados de cientificidade também exercem uma enorme influência nas formas como a mulher é interpretada no final do século XIX até a metade do século XX. São discursos produzidos pelos homens, que tomam as mulheres por objeto e constroem leituras que desprezam suas subjetividades, medicalizando seus corpos. ${ }^{7}$ Com isso, ajudaram a sustentar práticas de desigualdade e violência, pois muitos afirmaram a inferioridade física, moral e /ou intelectual das mulheres. Mesmo aqueles que não afirmaram diretamente a inferioridade colocaram a questão da diferença reforçando qualidades, atributos e condutas que seriam inerentes à mulher e estariam de acordo com a feminilidade. $O$ fato é que a discussão colocou a questão da diferença entre os sexos de forma proeminente, mas não trouxe à tona a discussão acerca das desigualdades de diretos e oportunidades entre mulheres e homens. A consequência direta pode ser percebida ainda nos dias de hoje, pois as mulheres recebem salários menores, fazem dupla jornada de trabalho, possuem pouca representatividade na política tradicional, sofrem discriminação de gênero nos meios profissionais, violência doméstica em diversos níveis e violência sexual.

Nos anos 1980 as acadêmicas começaram a utilizar a noção de gênero ${ }^{8}$ como uma estratégia para referir-se à organização social da relação entre os sexos com a finalidade de desvelar as relações de poder que intervém na construção do sistema sexo/gênero. Essas relações de poder se dão em muitos espaços da vida social, cultural, do trabalho e econômica. De maneira geral, as mulheres têm ocupado um lugar subalterno nesses espaços, gerando assim relações desiguais.

As pesquisadoras estavam preocupadas com o fato de que a produção dos estudos feministas se centrava sobre as mulheres de forma estreita e isolada e passaram a utilizar o termo gênero para introduzir uma noção relacional em nosso vocabulário analítico. Nessa perspectiva as mulheres e os homens são definidos em termos recíprocos, e nenhuma compreensão de qualquer um dos dois existe através do estudo separado de cada um deles. Tal abordagem é considerada como um avanço diante do conceito de patriarcado, em uso desde os anos 1960, uma vez que esse conceito vetorizou as relações de dominação e exploração de homens para mulheres sem se interessar necessariamente por

sobre Museologia e gênero no Brasil. In: Revista do Centro de Pesquisa e Formação, n. 5. São Paulo: SESC/SP, 20I7, pp: 6I-77.

7 Conforme assinala Mireille Dottin-Orsini, Cesare Lombroso, no prefácio de La Femme criminelle et la prostituée (1895) explica a coexistência na mulher da crueldade e da caridade pela influência da maternidade, que, enxertada na crueldade primitiva, faz muitas vezes brotar a doçura.Ver: Dottin-Orsini. Mireille. A mulher que eles chamavam fatal: textos e imagens da misoginia fin-de-siècle. Rio de Janeiro: Rocco, 1996.

8 Como assinala Joan Scott (1995) e mais recentemente Heleieth Saffioti (2009) o uso do termo gênero como substituto para mulheres ou história das mulheres pode acarretar neutralidade e distanciamento da política do movimento feminista, não designando necessariamente a tomada de posição sobre a desigualdade, o poder, a dominação/exploração e violência contra a mulher. É preciso que a pesquisa deixe claro seu posicionamento quanto a essas questões. Entretanto, fazemos a ressalva de que o oposto também se dá, ou seja, trabalhos que tratam de mulheres e suas histórias e trajetórias, mas que não operacionalizam o conceito de gênero podem não problematizar a condição de ser mulher, naturalizando o que Beauvoir chama de "condição feminina". Por mais que o uso do conceito de gênero traga o risco de tornar opaco o termo mulher ele abre a possibilidade de problematizar as mulheres, suas situações e atuações. 
ver como essa violência se operava em termos de troca ou mesmo cumplicidade.

Segundo Joan Scott, "talvez o mais importante, o gênero era um termo proposto por aquelas que defendiam que a pesquisa sobre mulheres transformaria fundamentalmente os paradigmas no seio de cada disciplina." (Scott, 1995: 73). Percebe-se um esforço para que o termo gênero pudesse ser desenvolvido como uma "categoria de análise". Nesse sentido, seguiria a linha traçada pelos estudos culturais nesse mesmo período (década de 1980 em diante) articulando ainda uma interface de interesses e pesquisas com os termos classe social, raça/etnia, sexo/opção sexual no que se convencionou chamar de interseccionalidade. Entretanto, constatamos que "gênero" não tem sido explorado nos estudos museológicos sobre coleções mesmo considerando que há uma extensa bibliografia na Museologia e áreas afins que trata do colecionismo e analisa essa prática sob pontos de vista variados.

\section{Coleções e museus são operadores da lógica androcêntrica}

No verbete sobre coleção do Dictionnaire encyclopédique de muséologie, a coleção, material ou imaterial, é tida "como o coração das atividades do museu" (DICTIONNAIRE, 20I0:53) e a definição de coleção que se apresenta é a seguinte:

\footnotetext{
De manière gènèrale, une collection peut être définie comme un ensemble d'objets matériels ou immatériels (oeuvres, artefacts, mentefacts, spécimens, documents d'archives, témoignanes, etc.) qu'un individu ou un établissement a pris soin de rassembler, de sélectionner, de classer, de conserver dans un context sécurisé et plus souvent de communiquer à un public plus ou moins large, selon qu'elle est publique ou privée. (DICTIONNAIRE, 2010:53) ${ }^{9}$
}

Admitir a centralidade das coleções nos museus e processos museológicos traz questionamentos de níveis diversos acerca das políticas de aquisição e nesse artigo colocamos a questão sobre a existência ou não de equidade nos documentos e objetos que façam referência à história e memória das mulheres nas políticas de aquisição efetuadas pelos museus. Segundo Yves Bergeron, "Lorsqu'on examine attentivement la constitution des collections des grans musées, on constate qu'elles sont le fruit du travail de collectionneurs." (Bergeron, 20I0: 55). O longo verbete sobre coleção do Dictionnaire encyclopédique de muséologie aborda os fundamentos da coleção, os colecionadores como "caçadores de tesouros e memórias", a coleção e sua relação com o processo de musealização, tipologias de coleções e os "níveis" dos objetos musealizados. Entretanto, não faz referência a gênero e não aborda as mulheres como colecionadoras, algo que contribui para que a

9 De maneira geral, uma coleção pode ser definida como um conjunto de objetos materiais ou imateriais (obras, artefatos, mentefatos, espécimes, testemunhos, documentos de arquivo, amostras, etc.) que um indivíduo ou a instituição tem tomado o cuidado de reunir, selecionar, classificar, armazenar em um contexto seguro e mais frequentemente para se comunicar com um público mais ou menos amplo, dependendo se é público ou privado. (tradução da autora) 
Colecionismo a partir da perspectiva de gênero

prática colecionista seja naturalizada como algo próprio do universo masculino, ou ao menos seja vista como uma prática "neutra". Isso nos leva a confirmar que a discussão sobre gênero precisa ser melhor desenvolvida nos estudos sobre coleções e colecionismo. Também é necessário discutir a visibilidade dessas coleções nas exposições e a criação de instrumentos nos sistemas de documentação e catalogação que evidenciem campos de recuperação nos quais a informação sobre mulheres seja um campo informacional existente e relevante de buscas e pesquisas.

Por isso, nos interessa ir além para compreender a coleção também como resultado das relações de poder estabelecidas por meio das relações de gênero. Conforme afirma a historiadora Joan Scott, "gênero é uma forma primária de dar significado às relações de poder" (Scott, 1995: 85). Ora, no âmbito de um colecionismo ilustrado é possível admitir que as condições concretas para que uma mulher colecione podem ser diferentes daquelas encontradas pelo homem. A suposição pode ser melhor dimensionada se cotejada com três aspectos: a relativa dependência econômica da mulher no meio familiar, as condições de acesso à educação para a mulher no Brasil no final do século XIX até a primeira metade do século $X X$ e a existência de uma "cultura feminina" nesse mesmo período como uma poderosa moldura para o comportamento da mulher, tanto no sentido da adesão quanto da negação. Trata-se de perceber nesses três aspectos concepções explícitas e implícitas de gênero que funcionam como forças de condução na tomada de escolhas e posições e na definição das identidades.

A tese de Vânia Carneiro de Carvalho, intitulada "Gênero e Artefato: O sistema doméstico na perspectiva da cultura material - São Paulo, 18701920" defendida em 200I e orientada por Ulpiano Bezerra de Meneses no Departamento de História da Universidade de São Paulo (USP) trata da questão dos objetos e suas vinculações a universos femininos e masculinos. Ela aborda a cultura feminina na cidade de São Paulo entre os anos de 1870 a 1920 e o faz através da cultura material, em particular por meio da coleção do Museu Paulista e do Museu da Casa Brasileira, que ela analisa de forma comparada a materiais publicitários e manuais femininos e de civilidade publicados e veiculados em São Paulo no mesmo período. Sua hipótese central era a "verificação de um relacionamento simbiótico entre os objetos domésticos e a formação de identidades sociais diferenciadas pelo gênero." (Carvalho, 2008: 25).

No prefácio da tese em questão, publicada em livro, Ulpiano Bezerra de Meneses pondera que "Analisar as questões de gênero sem a dimensão material que lhes dá viabilidade social é reduzi-las a fenômenos psíquicos ou mentais enclausurados ou a dogmatismos sem raízes no chão concreto em que vivem os homens como seres sociais" (Meneses, 2008: I2). É aí também que reside nosso esforço em analisar o colecionismo a partir do gênero, pois entendemos que tanto os objetos colaboram para instituir ou reproduzir os papéis de gênero quanto o próprio gênero institui papéis a serem desempenhados pelos objetos e coleções. Esse aspecto liga-se a problemática acerca das diferenças entre os tipos de objetos escolhidos por mulheres e homens para reunirem suas coleções entendendo que tais escolhas estão identificadas com os valores e identidades atribuídos àquilo que se projeta nos universos das culturas feminina e masculina. Desta forma, estende-se e relaciona-se também aos tipos de objetos 
que chegam de fato aos museus e quais as memórias das mulheres podem ser construídas e contadas nessas instituições a partir desses objetos e coleções.

Entendemos que os museus escolhem representar os gêneros de determinadas formas, de modo a reiterar as relações e os lugares de mulheres e homens na sociedade. Com isso reforçam ideias e mesmo as excepcionalidades podem reiterar a ordem social hegemônica. O exemplo das canetas relatado por Vânia é bem expressivo da redução operada nos museus a esse respeito. Ao abordar o espaço dos escritórios domésticos e sua organização a autora observa que

\begin{abstract}
O acervo do Museu Paulista está repleto de canetas feitas de metal e pedrarias nobres, que pertenceram a proeminentes figuras da política e da cultura nacional - Prudente de Moraes, Campos Salles, Pedro de Toledo, Américo Brasiliense, Wenceslau Brás, Bernardino de Campos, Santos Dumont e Altino Arantes. É interessante o fato de que nesta tipologia não aparece uma só peça que tenha pertencido a uma mulher. (...) (Carvalho, 2008: 52)
\end{abstract}

Ora, se museus constroem seus discursos a partir de coleções e objetos negligenciando um aspecto tão estruturante das relações e práticas sociais como são as relações de gênero, eles abrem mão de uma postura crítica e endossam a hegemonia do patriarcado ao silenciarem continuamente as mulheres e amplificarem as vozes e ações dos homens, chegando a construir uma "política da masculinidade" ${ }^{10}$ (Connel, 1995).

Os museus significam relações de poder ao preservarem referências culturais e o fazem numa esfera muito influente que é a simbólica. Essa esfera simbólica atua no reforço de convenções socialmente aceitas, produzidas e reproduzidas. Essa esfera simbólica também tem um papel importante na modelagem de identidades individuais e coletivas, inclusive nas de gênero. A política da masculinidade também é uma convenção socialmente aceita, de caráter simbólico, portanto essa política passa como verdade na medida em que é naturalizada e não questionada.

As relações de poder no museu são assimétricas em especial porque são hierarquizadas, mas também porque não consideram, na maioria das vezes, as diferenças como fundamento para ações de preservação. Pode-se pensar que os museus simplesmente espelham as assimetrias presentes na sociedade, mas o

I0 Para Robert Connel, até o final da década de 70, os estudos sobre sexualidade e masculinidade reforçaram historicamente o chamado "papel masculino" como um conjunto de atitudes e expectativas que definiam a masculinidade apropriada. Esse conceito tornou-se obsoleto por não permitir ver a existência de múltiplas formas de masculinidade. Para o autor, a masculinidade é "uma configuração de prática em torno da posição dos homens na estrutura das relações de gênero." (1995, p. 188). Políticas da masculinidade refere-se a todo tipo de prática (produção/ reprodução) cuja ação envolve uma racionalidade e um significado histórico na manutenção ou reprodução da posição dominante dos homens na estrutura das relações de gênero.A discussão envolve ainda a admissão de que existe uma determinada forma hegemônica de masculinidade com outras masculinidades agrupadas em torno dela. Para o autor, discutir gênero e masculinidade implica não apenas na relação entre homens e mulheres, mas também a ênfase de que gênero é uma estrutura complexa que engloba a economia e o estado bem como a família e a sexualidade.Ver: CONNELL, Robert W. Políticas da Masculinidade. In: Educação e Realidade, vol. 20, 1995, pp: I85-206. 
Colecionismo a partir da perspectiva de gênero

fato é que os museus são instâncias de criação e consolidação de normas, valores e padrões sociais. $O$ problema da negação ou da omissão do gênero nos museus liga-se à intencionalidade das práticas realizadas por essas instituições e dentre outros problemas evidencia seu papel na construção relacional da configuração do que seja a performatividade das identidades feminina e masculina. A negação do gênero nos museus não significa que essa problemática não esteja presente nessas instituições (porque ela está presente mesmo quando ausente, ou seja, quando não é assumida), mas revela a falta de intencionalidade dessas instituições em lidar com essa dimensão das relações humanas. Em última análise é preciso admitir que tanto as mulheres quanto os homens experimentam os duros limites impostos pelas rígidas definições de valores masculinos e femininos propagados como normas de conduta e interação social. Os museus podem ser lugares para colaborar na concretização de vivências e experiências que configuram essas práticas de constituição de identidades e pertencimento de forma mais crítica e igualitária.

Por isso, aplicar o conceito de gênero aos museus e coleções possibilita questionar as formas como a memória é construída tanto pelos objetos que estão presentes, quanto pelos que estão ausentes nos museus. Percebe-se que a crítica é radical e relacional e deve ser operada no plano da memória enquadrada (Pollak, 1989) e no do esquecimento, tanto para mulheres quanto para os homens. Neste sentido, gênero não é um tema ou um enfoque, é um conceito que coloca em xeque aspectos ligados às identidades, ao poder, à produção científica e ao conhecimento, que pode auxiliar a reposicionar os museus nos debates contemporâneos sobre representatividade e desigualdade subvertendo a lógica hegemônica e androgênica que essas instituições legitimam.

Em seu artigo "Gênero e consumo cultural nos museus", Luz Maceira Ochoa analisa empiricamente dois museus nacionais mexicanos: o Museu Nacional de Antropologia (MNA) e o Museu Nacional de Historia e afirma:

Aunque este tipo de museos se hayan reconocido como dispositivos de ideologización, pocas veces se asume que su sesgo político está marcado por un discurso de género, usualmente androcéntrico, pues el museo no es ajeno a la organización social y de género en la sociedad que se construye. (Ochoa, 2008: 210)"1.

Analisar os museus inseridos na dinâmica social e no sistema patriarcal do qual fazem parte é condição para que o olhar sobre eles não seja conformador, acrítico, anacrônico e colabora para perceber as dimensões política e ideológica presentes em seus discursos e práticas. Com isso, lançamos para os museus um olhar crítico ao questionar a invisibilidade e a ausência de pesquisas associadas às mulheres como colecionadoras contribuindo para a desconstrução da lógica androcêntrica e patriarcal que ainda impera nas políticas de construção da memória em nossa sociedade.

A lógica androcêntrica refere-se principalmente à forma como as

II Embora estes tipos de museus tenham sido reconhecidos como dispositivos de ideologização, raramente se assume que seu viés político é marcado por um discurso de gênero, geralmente androcêntrico, pois o museu não é alheio à organização social e de gênero da sociedade em que é construído. (tradução da autora) 
experiências masculinas são consideradas como as experiências de todos os seres humanos e tidas como uma norma universal, tanto para homens como para mulheres, sem dar o reconhecimento completo e igualitário à sabedoria e experiências femininas. Essa lógica é estruturante das relações sociais e sustenta as práticas, discursos e normas presentes no sistema patriarcal. É utilizada para descrever ou apontar não atitudes individuais ou setores precisos da vida social, mas um sistema que impregna e comanda o conjunto das atividades humanas, coletivas e individuais. Neste sentido, no conjunto do léxico feminista, tanto militante quanto teórico, não se confunde com os termos "machismo" ou "sexismo" que denotam mais o nível das atitudes e/ou das relações interindividuais, ainda que possam ser utilizados de forma complementar em análises explicativas sobre as relações de hierarquia presentes nas relações de gênero.

\section{Retirar o véu: mulheres e coleções}

A historiadora Michelle Perrot em seu artigo "Práticas da memória feminina" nos diz que as mulheres têm a "paixão das coisas". Ela quer dizer sobre as práticas de memória das mulheres para além da escrita, e fala um pouco sobre objetos e coleções. Segundo a autora,

\footnotetext{
É ao mundo mudo e permitido das coisas que as mulheres confiam sua memória. Não aos prestigiosos objetos de coleção, coisas de homens ansiosos por conquistar pela acumulação de quadros ou de livros a legitimidade do gosto. No século XIX, a coleção, mais ainda a bibliofilia são atividades masculinas. As mulheres se dedicam à matéria mais humilde: à roupa e aos objetos, bugigangas, presentes recebidos por ocasião de um aniversário ou de uma festa, bibelôs trazidos de uma viagem ou de uma excursão, "mil nadas" povoam as cristaleiras, pequenos museus da lembrança feminina. As mulheres têm paixão pelos porta-joias, caixas e medalhões onde encerram seus tesouros: mechas de cabelo, joias de família, miniaturas que, antes da fotografia, permitem aprisionar o rosto amado. (Perrot, 1989: 13)
}

Bem, Perrot não se dedicou ao estudo de museus, objetos e coleções em particular, sua reflexão nesta área pode parecer pouco profunda, mas ela nos dá algumas dicas nessa passagem. Em primeiro lugar, ela identifica o colecionismo como uma atividade masculina, ao menos até o século $\mathrm{XIX}$ e parece entender que os homens colecionam de forma sistemática, organizada e científica, enquanto as mulheres colecionam na verdade recordações e lembranças por meio dos objetos. A generalização operada por Perrot não nos parece totalmente equivocada considerando a formação diferenciada de meninas e meninos quanto à escolaridade e o incentivo de interesses no fortalecimento de identidades femininas e masculinas, mas é preciso olhar para o universo do colecionismo ilustrado com mais atenção para compreendê-lo.

Segundo Maria Bolaños Atienza em seu artigo "Las mujeres em los museos: entre museólogas y coleccionistas”, na Europa tem-se conhecimento 
Colecionismo a partir da perspectiva de gênero

de mulheres que colecionam obras de arte desde o século $X V$, ainda que seja preciso distingui-las das vidas de seus pais e maridos com as quais se misturam, tarefa nem sempre fácil. Destaca-se em 1737 decisões pioneiras como a de Anna Ludovica de Medici, uma ilustrada moderna, que doou a fabulosa coleção familiar à cidade de Florença convertendo os Uffizi em um dos primeiros museus públicos do mundo (Atienza, 201 I:37).

Segundo a autora, tanto na Europa quanto nos Estados Unidos, o papel das mulheres colecionadoras é de destaque e muitas vezes pioneiro, principalmente no âmbito das artes, em especial das vanguardas artísticas. Entretanto, a história dessas colecionadoras ainda é pouco dimensionada na história e também pouco conhecida.Ademais, afora exemplos de grandes colecionadoras, a autora destaca o papel das mulheres como colecionadoras em âmbito doméstico para quem a atividade de colecionar representava uma espécie de passatempo incentivado nos meios familiares como forma de ocupação. Segunda ela, a grande fratura neste campo, quando pela primeira vez as mulheres se destacam com voz própria no âmbito do colecionismo, foi entre os anos 1870 a 1930. De fato, segundo Atienza, trata-se de um cenário complexo expresso da seguinte forma

$Y$ es que el acceso de las mujeres al coleccionismo artístico es el producto de su marginalidad. (...) Pero, paradójicamente, la gestión de una colección de arte y, por extensión, la de los museos, ha terminado por servir, históricamente, como una reserva de emancipación estética e íntima, casi secreta. Ha permitido a muchas mujeres asomarse al mundo, promocionar su personalidad, hacerse respetar, crearse un campo de decisión donde aplicar inteligencia y razón, despertar entre la gente sentimientos de admiración, envidia o curiosidad; $y$, en suma, tener un nombre propio y una presencia social (más difícil de obtener, sobre todo en las primeras generaciones, em el caso de mujeres solteras). (Atienza, 20I I:4I) 12

É interessante a observação da autora de que a prática do colecionismo estaria vinculada à marginalidade das mulheres no meio artístico ao mesmo tempo em que permitia sua emancipação. Essa interpretação reforça a importância de estudarmos o colecionismo como prática social e como tal vinculá-lo às relações de gênero buscando assim novas formas para compreender tanto o histórico de determinadas coleções quanto as condições para que fossem reunidas.

Sabemos que no século XIX, no Brasil, algumas coleções foram reunidas por mulheres. As mais conhecidas, das quais nos chegam relatos e estudos são a Coleção da Imperatriz Leopoldina e a Coleção Teresa Cristina Maria, mulheres da mais alta esfera da nobreza imperial. Sobre a Imperatriz Leopoldina (I797-1826), o estudo de Arilda Inês Miranda Ribeiro "Desafios da pesquisa com gênero de escritos: memória e correspondências educativas da Imperatriz

I $2 \mathrm{E}$ assim que o acesso das mulheres ao colecionismo artístico é produto de sua marginalidade. (...), mas, paradoxalmente, a gestão de uma coleção de arte e, por extensão, dos museus, terminou por servir, historicamente, como uma reserva de emancipação estética e íntima, quase secreta. Permitiu que muitas mulheres se aproximassem do mundo, promovendo a sua personalidade, fazendo-se respeitar, criando um campo de decisão para aplicar a inteligência e a razão, despertando entre as pessoas sentimentos de admiração, inveja ou curiosidade; e, em suma, ter um nome e uma presença social (mais difícil de obter, especialmente nas primeiras gerações, no caso de mulheres solteiras) (tradução da autora) 
Leopoldina no século XIX”, ao analisar seus diários e correspondências, ressalta o interesse da jovem, ainda em Viena, por assuntos científicos como a botânica, fauna e minerais. Em 1817 quando chega ao Brasil já casada por procuração com D. Pedro I traz seu enxoval, sua biblioteca, sua coleção e presentes. Tinha grande interesse por História Natural e no Brasil colecionava sistematicamente orquídeas, moluscos e minerais, tendo organizado a Biblioteca nas salas do Paço da Boa Vista, em que avultavam obras de Mineralogia e Botânica ${ }^{13}$..

A Imperatriz Teresa Cristina Maria, casou-se com D. Pedro II em I843. Em seu artigo "Teresa Cristina de Bourbon (1822-1899): a fase oculta da imperatriz silenciosa", Lucia Maria Paschoal Guimarães ressalta que além do interesse pelas artes e ciências de modo geral

(...) a maior contribuição da imperatriz ao patrimônio cultural brasileiro foi a coleção que tomou o seu nome, hoje ao abrigo no Museu Nacional. São cerca de 700 itens, a maioria em cerâmica e terracota, além de objetos em bronze, vidro, osso, marfim, âmbar, quatro afrescos, e um busto em mármore. $O$ grande destaque são as estatuetas femininas em terracota, dos sécs. IV-III a.C., os cântaros italiotas do séc. IV a.C., um cálice etrusco, cuja datação aproximada situa-se entre 620 - 580 a.C. Fruto do fascínio de d.Teresa Cristina pela arqueologia, constitui o maior acervo da antiguidade grecoromana existente na América Latina. (Guimarães, 201 I:07)

Outro caso é a Coleção de pinturas em miniaturas de Amélia Machado de Coelho e Castro,Viscondessa de Cavalcanti ${ }^{14}$ (I852-1946), que se encontra no Museu Mariano Procópio em Juiz de Fora/MG. É uma coleção bem conhecida e por mais que nos parece exemplar não significa que seja exceção. Ainda que a coleção da Viscondessa esteja centrada principalmente em uma tipologia de objetos (pinturas de miniaturas) que segundo Perrot seria alvo especial de interesse pelas mulheres, a Viscondessa foi uma colecionadora com muitos interesses inclusive pela numismática e mineralogia.

Também uma coleção importante de registrar é a Coleção Sophia Jobim ${ }^{15}$

I3 Ver: RIBEIRO, Maria Inês Miranda. Desafios da pesquisa com gênero de escritos: memória e correspondências educativas da Imperatriz Leopoldina no século XIX. Pesquisa de Pós-Doutoramento na Unicamp. Disponível em: www.faced.ufu.br.Acesso em 03/01/2018.

I4 Amélia Machado de Coelho e Castro, Viscondessa de Cavalcanti, foi uma estudiosa, colecionadora sistemática e a sexta mulher a ingressar no Instituto Histórico e Geográfico de São Paulo. Autora do "Catalogo das Medalhas Brazileiras e das Estrangeiras Referentes ao Brazil" editado em Paris em 1910.

I5 Sophia Jobim Magno de Carvalho foi educadora, museóloga, jornalista, colecionadora, professora de Indumentária Histórica da Escola Nacional de Belas Artes (ENBA). Fundou em 1932 o Liceu Império, importante escola profissionalizante de corte e costura no Rio de Janeiro. Criou em 1960 o Museu de Indumentária Histórica que funcionava em sua residência no bairro de Santa Teresa/RJ. Foi fundadora do Clube Soroptimista em 1947 juntamente com Bertha Lutz com quem dividiu ainda a vice-presidência da Federação Brasileira para o Progresso Feminino (FBPF). Sua coleção (de trajes, documental e bibliográfica) é considerada a terceira maior coleção do MHN ao lado das Coleções Gustavo Barroso e Miguel Calmon e foi doada ao MHN em 1968 após seu falecimento. Para maiores informações sobre sua biografia ver: Dicionário das Mulheres no Brasil, p. 50I.Ver também: OLIVEIRA,Ana Cristina Audebert Ramos de. Gênero, mulher e indumentária no museu: A Coleção Sophia Jobim do Museu Histórico Nacional. (Tese de Doutorado). Programa de Pós-Graduação em Museologia e Patrimônio. UNIRIO/MAST, 2018. 
Colecionismo a partir da perspectiva de gênero

(1904-1968) do Museu Histórico Nacional/RJ. Especializada em indumentária, da qual destacamos a presença de bonecas miniaturas em trajes etnográficos, a coleção evidencia o trânsito de interesses entre as disciplinas de Etnografia e Indumentária ao longo das décadas de 1940, 1950 e 1960, décadas nas quais Sophia exerceu de forma sistemática sua prática colecionista. A coleção deu origem ao Museu de Indumentária Histórica criado pela colecionadora em sua residência e inaugurado em 1960. Vale ressaltar também a Coleção de Indumentária reunida por Henriqueta Martins Catarino'6 (I886-1969) e que deu origem ao Museu do Traje e do Têxtil da Fundação Instituto Feminino da Bahia em Salvador. Ligada diretamente ao acervo do IFB, um outro exemplo desse trânsito de interesse entre as disciplinas de Indumentária e Etnografia é o trabalho de Heloísa Alberto Torres" (1895-1977) "Alguns aspectos da indumentária da crioula baiana" apresentada pela pesquisadora ao concurso para provimento da cadeira de Antropologia e Etnografia da Faculdade Nacional de Filosofia da Universidade do Brasil em 1950. Apesar de precursora da Antropologia no Brasil foi vetada pela congregação por não possuir título superior - Heloísa era autodidata. A pesquisa sobre indumentária volta-se para a análise formal do pano da costa e demais nuances da indumentária crioula tais como as rendas, aspectos decorativos e demais adereços, e é realizada com base no acervo do Instituto Feminino da Bahia (IFB) como aponta a autora no início de seus trabalhos,

As coleções de vestimentas de crioulas baianas, pertencentes ao Instituto Feminino da Bahia, em Salvador, foram minuciosamente estudadas. $\bigcirc$ material não poderá ser totalmente utilizado neste trabalho; selecionamos o que de mais expressivo encontramos para esclarecimento de tópicos determinados. (Torres, 2004:416).

Há ainda muitos casos que poderiam ser citados de colecionadoras sistemáticas como o de Eva Klabin Rapaport ${ }^{18}$ (1903-199I) que inclusive mantém com Sophia Jobim a semelhança de ter criado um museu de sua coleção em sua própria residência. Entretanto, é ainda Michelle Perrot quem afirma que "Organizar arquivos, conservá-los, guardá-los, tudo isso supõe uma certa

16 Henriqueta Martins Catharino. Foi educadora e seu principal objetivo era proteger a mulher trabalhadora, tendo investido em cursos de corte e costura e datilografia para jovens mulheres. Desta experiência nasceu o Instituto Feminino da Bahia. Em I931, com o objetivo de preservar a arte popular, adquiriu uma coleção de esculturas de madeira executada por artistas de Santo Estevão de Jacuípe e também de obras em cerâmica, dando início ao primeiro Museu de Arte Popular, primeiro do gênero na Bahia. Para maiores informações sobre sua biografia e obras ver: Dicionário das Mulheres no Brasil, p. 265.

17 Heloísa Alberto Torres. Antropóloga. Em 1918 foi para o Museu Nacional, como estagiária de Roquete Pinto para prosseguir seus estudos, destacando-se por sua competência e dedicação. Em 1925 foi aprovada em primeiro lugar para professor substituto da divisão de Antropologia, Etnografia e Arqueologia do Museu Nacional. Por seus estudos sobre cerâmica marajoara tornou-se uma autoridade em cerâmica respeitada internacionalmente. Em 1938, sucedendo Roquete Pinto, assumiu a direção do Museu Nacional, cargo que ocupou por duas décadas. Para maiores informações sobre sua biografia e obras ver: Dicionário das Mulheres no Brasil, p. 262.

18 Colecionadora sistemática, de família rica, suas primeiras aquisições começam em 1947. Com a morte do marido em 1957 passa a dedicar-se quase que exclusivamente à sua coleção fazendo frequentes viagens à Europa para adquirir novas peças. Em 1995 a Fundação Eva Klabin foi aberta ao público e mantém uma das mais importantes coleções de arte europeia existentes no Brasil. 
relação consigo mesma, com sua própria vida, com sua memória. Pela força das coisas é um ato pouco feminino. A perda, a destruição, a auto-destruição são muito frequentes." (Perrot, 20I2: 30). Entretanto, o que nos ocorre também é que diante de uma perspectiva de gênero, essa organização de arquivos e sua conservação se dá numa perspectiva relacional. É expressiva a pesquisa de mestrado de Regina Abreu (1996) publicada em livro cujo título é "A Fabricação do Imortal". Nele, a autora analisa a "grande e suntuosa" Coleção Miguel Calmon du Pin e Almeida que foi doada ao Museu Histórico Nacional em 1936 por Alice da Porciúncula Calmon du Pin e Almeida após o falecimento de seu marido. A autora deixa claro que a ideia da doação partiu de sua esposa Alice. ${ }^{19}$ Mesmo que Regina Abreu não tenha desenvolvido sua pesquisa a partir das questões de gênero, uma vez que não era esse seu objetivo, fica óbvio que a memória de Miguel Calmon foi construída por sua esposa. Selecionada por ela, condicionada nas suas exigências inclusive quanto às formas de expor e organizar os objetos. Trata-se, portanto, de perspectivas complementares quanto aos olhares que são aplicados na análise de coleções em museus e instituições congêneres quando vistos a partir da perspectiva de gênero. $O$ protagonismo das mulheres pode não residir exatamente na reunião de objetos sobre sua própria trajetória, mas pode ser exercido também na organização e seleção de coleções de homens com quem compartilhavam suas vidas, tais como seus colegas de trabalho, irmãos, maridos, amantes ou pais. Trata-se de um vasto campo a ser investigado, muito complexo e que comporta análises diferenciadas e um olhar cuidadoso. Afinal, nos parece que a história das coleções e do colecionismo no Brasil, mas não só, precisa ser recontada do ponto de vista dos estudos de gênero e das mulheres e evidenciando seus lugares, suas lógicas e a importância de suas práticas como colecionadoras.

Voltando à citação de Perrot e em segundo lugar, cumpre ainda assinalar que ela parece indicar uma valoração na tipologia de objetos de coleções reunidas por mulheres e homens. A dos homens seriam mais sistemáticas e científicas enquanto a das mulheres seriam "mil nadas", bugigangas ou objetos de recordação de viagens. Essa nos parece uma ideia se não equivocada, ao menos parcial, pois o ato de colecionar pode ocorrer de forma sistemática tanto por mulheres quanto por homens. Porém, há pesquisas que parecem também localizar uma recorrência de interesses quanto aos tipos de objetos reunidos por mulheres e homens (Belk and Wallendorf, 2003: 240). Em parte, isso pode ser compreendido a partir da construção social do que é reforçado como identidades femininas e masculinas de forma dominante na cultura ocidental. Segundo o estudo,

\footnotetext{
Thus, collecting is a means of achieving and expressing identity. Gender is implicated in this process in several ways, three of which we discuss here. Gender is linked to collecting through the gendered meaning of essential collecting activities, the gender associations of
}

I9 Segundo a autora, Alice da Porciúncula confidenciou ao sobrinho, Pedro Calmon (que na época trabalhava no Museu Histórico Nacional) a intenção de fazer uma doação ao museu dos bens que pertenceram ao marido Miguel Calmon. A partir daí iniciou-se uma troca de correspondências e em 1936 a Coleção Miguel Calmon foi definitivamente incorporada ao Museu Histórico Nacional, na época sob a direção de Gustavo Barroso.Ver:ABREU, Regina. A Fabricação do Imortal: memória, história e estratégias de consagração no Brasil. Rio de Janeiro: Rocco: Lapa, 1996, páginas, 25, 26 e 27. 
Colecionismo a partir da perspectiva de gênero

the objects collected, and the gendered uses of collections. (Belk and Wallendorf, 2003: 24I)

Ou seja, o ato de colecionar está ligado com o processo de construção e expressão de identidades, e gênero está implicado nesse processo, tanto das identidades quanto do colecionismo. Por isso, nesse artigo reforçamos a importância de estudar e discutir o colecionismo, enquanto pratica social, condicionado pelas relações de gênero. Para James Clifford, “(...) a identidade, seja cultural ou pessoal, pressupõe os atos de colecionar, de reunir posses em sistemas arbitrários de valor e significado. Esses sistemas, sempre poderosos e governados pelas normas, mudam historicamente." (Clifford, 1994:7I) A constatação de que esses sistemas mudam historicamente nos impulsiona a refletir sobre os lugares das mulheres como colecionadoras, seja nos museus ou não, colocando em evidência suas coleções e suas trajetórias.

\section{Considerações finais}

Este artigo buscou evidenciar a importância e a viabilidade de articular o estudo sobre coleções e colecionismo com os estudos de gênero, feministas e das mulheres. Não buscamos responder questões, mas procuramos abrir caminhos e estimular inquietações e reflexões sobre as relações entre gênero, memória, museus e coleções. Nos perguntamos: como é que gênero dá sentido à construção, percepção e organização da memória social? E ainda, como é que os museus e a Museologia percebem esse debate e participam dele? Uma das formas de entrar nesse debate é através de pesquisas sobre coleções e colecionismo. Se conseguimos evidenciar a atuação das mulheres como colecionadoras suas trajetórias ganham novos contornos. Ao estudarmos as coleções que reuniram compreendemos melhor as memórias que construíram e organizaram, contribuindo para uma história crítica do colecionar. Com isso, lançamos para os museus e para os estudos sobre coleções um olhar mais abrangente e emancipado e podemos questionar a invisibilidade e a ausência de pesquisas associadas às mulheres como colecionadoras.

\section{Referências}

ABREU, Regina. A Fabricação do Imortal: memória, história e estratégias de consagração no Brasil. Rio de Janeiro: Rocco: Lapa, 1996. Acesso em: 24 out. 2017.

ATIENZA, Maria Bolaños. Las mujeres en los museos: entre museólogas y coleccionistas. In: Patrimonio em feminino. Espanha, 20 I I, pp: 36-47.

BARROSO, Gustavo. Introdução à Técnica de Museus. Ministério da Educação e Saúde. Rio de Janeiro: Gráfica Olímpica, I 951.

BAUDRILLARD, Jean. O sistema dos objetos. São Paulo: Perspectiva, 2006.

BEAUVOIR, Simone. O Segundo Sexo. Rio de Janeiro: Nova Fronteira, 2009.

BELK, Russell; WALLENDORF, Melanie. Of mice and men: gender identity in collecting. In: PIERCE, Susan. (Org.) Interpreting Objects and Collections. New York: Taylor e Francis E-Library, 2003. 
CARVALHO, Vânia Carneiro de. Gênero e Artefato: O Sistema doméstico na perspectiva da cultura material - São Paulo: 1870-1920. São Paulo: Editora da Universidade de São Paulo/Fapesp, 2008.

CLIFFORD, James. Colecionando arte e cultura. Revista do Patrimônio Histórico e Artístico Nacional, v. 23, p. 69-89, 1994.

CONNELL, Robert W. Políticas da Masculinidade. Educação \& Realidade. Porto Alegre, vol. 20, n² 2, p. 185-206, 1995.

COSTA, Angelita Maria Rocha Ferrari da. A coleção de pintura em miniatura da Viscondessa de Cavalcanti no Museu Mariano Procópio. Juiz de Fora, 2010, (Dissertação). Mestrado em História. Universidade Federal de Juiz de Fora.

DEL PRIORI, Mary. Histórias íntimas. Sexualidade e erotismo na história do Brasil. São Paulo: Editora Planeta do Brasil, 201 I.

DESVALLÉS, Andre; MAIRESSE, François. (Eds.) Dictionnaire Encyclopédique de Muséologie. Paris:Armand Collin, 20II.

DOTTIN-ORSINI, Mireille. A mulher que eles chamavam fatal: textos e imagens da misoginia fin-de-siècle. Rio de Janeiro: Rocco, 1996.

GUIMARÃES, Lucia Maria Paschoal. Teresa Cristina de Bourbon (I822-I889): a face oculta da imperatriz silenciosa. In: Anais do XXVI Simpósio Nacional de História, 20 I I. Disponível em: www.snh20 I I.anpuh.org. Acesso em 03/0 I/20 I8.

HELLER,Agnes. O Cotidiano e a História. São Paulo: Editora Paz e Terra, 2000.

HIRATA, Helena. (et al.) (Orgs). Dicionário Crítico do feminismo. São Paulo: Editora UNESP, 2009.

LOPES, Maria Margaret. Bertha Lutz e a importância das relações de gênero, da educação e do público nas instituições museais. In: Musas-Revista Brasileira de Museus e Museologia. 2006, pp: 4I-47.

MACEIRA OCHOA, Luz. Género y consumo cultural en museos: análisis y perspectivas. La ventana, Guadalajara, v. 3, n. 27, p. 205-230, jul. 2008. Disponível em: $\quad$ http://www.scielo.org.mx/scielo.php?script=sci_arttext\&pid=SI40594362008000 I 00008\&lng=es\&nrm=iso.Acesso em: 24 out. 2017

MAGALHÃES, Aline M; BEZERRA, Rafael Z. (Orgs.) Coleções e colecionadores: a polissemia das práticas. Rio de Janeiro: Museu Histórico Nacional, 2012.

MAIA, Diogo Correia. A importância dos colecionadores de arte para a Museologia. Um estudo de caso: Eva Klabin Rapaport. In: III Encontro de História da Arte - IFCH/UNICAMP, 2007, p. 375-382. Disponível em: http://www.unicamp. br/chaa/eha/atas/2007/MAIA,\%20Diogo\%20Correa.pdf . Acesso em: 25 out. 2017.

NOVINSKY, Anita. A inquisição. São Paulo: Editora Brasiliense, 1982.

OLIVEIRA, Ana Cristina Audebert Ramos de; QUEIROZ, Marijara Souza de. Museologia - Substantivo Feminino: Reflexões sobre Museologia e gênero no 
Colecionismo a partir da perspectiva de gênero

Brasil. In: Revista do Centro de Pesquisa e Formação, n. 5. São Paulo: SESC/SP, 20I7, Pp: 6I-77. Disponível em https://centrodepesquisaeformacao.sescsp.org.br/ revista/.Acesso em 07/0I/20I8.

PEIXOTO,Ana Lúcia U;ALVES, Marieta; SOUZA, Maria Júlia A. (Orgs). Museu do Traje e do Têxtil. Salvador: Fundação Instituto Feminino da Bahia, 2003.

PERROT, Michelle. Práticas da memória feminina. Revista Brasileira de História (ANPUH). São Paulo: Marco Zero, p. 9- I8, 1989.

. Minha História das mulheres. São Paulo: Editora Contexto, 2012.

POLLAK, Michael. Memória, esquecimento, silêncio. Revista Estudos Históricos. Rio de Janeiro: vol. 2, n. 3, p. 3-15, 1989.

POMIAN, Krzysztof. Colecção. Enciclopédia Einaudi: memória - história. Lisboa: Imprensa Nacional - Casa da Moeda, p. 5 I-86, 1985.

RIBEIRO, Maria Inês Miranda. Desafios da pesquisa com gênero de escritos: memória e correspondências educativas da Imperatriz Leopoldina no século XIX. Pesquisa de Pós-Doutoramento na Universidade de Campinas. 2004/2005. Disponível em: www.faced.ufu.br.Acesso em 03/01/2018.

SAFFIOTI, Heleieth. Primórdios do conceito de gênero. Cadernos Pagu, n. I2, p. I57-163, 2015.

Ontogênese e filogênese do gênero: ordem patriarcal de gênero e a violência masculina contra mulheres. Série Estudos/Ciências Sociais/FLASCOBrasil, 2009. Disponível em http://www.flacso.org.br/portal/pdf/serie_estudos ensaios/Heleieth_Saffioti.pdf.

SCHUMAHER, Schuma; BRAZIL, Érico,V. (Orgs.) Dicionário Mulheres do Brasil: de 1500 até a atualidade biográfico e ilustrado. Rio de Janeiro: Editora Jorge Zahar, 2000.

SCOTT, Joan. Gênero: uma categoria útil de análise histórica. Educação e Realidade. Porto Alegre, vol. 20, n² 2, jul./dez. p. 7I-99, 1995.

TORRES, Heloísa Alberto. Alguns aspectos da indumentária da crioula baiana. Cadernos Pagu, n. 23, p. 4I3-467, 2004. (Documento).

VIANA, Fausto. Dos Cadernos de Sophia Jobim. Desenhos e estudos de história da moda e indumentária. São Paulo: Estação das Letras e C 